\title{
Yugur Chinese
}

National Cancer Institute

\section{Source}

National Cancer Institute. Yugur Chinese. NCI Thesaurus. Code C158205.

A Chinese person from the Yugur ethnic group. 